\title{
High prevalence and characterization of extended-spectrum ß-lactamase producing Enterobacteriaceae in Chadian hospitals
}

Oumar Ouchar Mahamat ${ }^{1,2,3^{*}}$ (D, Manon Lounnas ${ }^{1,2}$, Mallorie Hide ${ }^{2}$, Yann Dumont ${ }^{1}$, Abelsalam Tidjani ${ }^{4}$, Kadidja Kamougam ${ }^{5}$, Madina Abderrahmane ${ }^{6}$, Julio Benavides ${ }^{7}$, Jérôme Solassol ${ }^{8}$, Anne-Laure Bañuls ${ }^{2,9}$, Hélène jean-Pierre ${ }^{1}$, Christian Carrière ${ }^{1}$ and Sylvain Godreuil ${ }^{1,2,9}$

\begin{abstract}
Background: Extended-spectrum B-lactamase-producing Enterobacteriaceae (ESBL-PE) represent a major problem in the management of nosocomial infections. However, ESBL-PE are not systematically monitored in African countries. The aim of this study was to determine ESBL-PE prevalence in patients from three hospitals in N'Djamena, the capital city of Chad, and to characterize the genetic origin of the observed resistance.

Methods: From January to March 2017, 313 non-duplicate isolates were recovered from various clinical specimens obtained from 1713 patients in the three main hospitals of N'Djamena. Bacterial species were identified by matrixassisted laser desorption ionization-time of flight mass spectrometry. Susceptibility to 28 antibiotics was tested using the disk diffusion method on Müller-Hinton agar, and ESBL production was confirmed with the double-disc synergy test. The most prevalent ESBL genes associated with the observed resistance were detected using multiplex PCR followed by double-stranded DNA sequencing.

Results: Among the 313 isolates, 197 belonged to the Enterobacteriaceae family. The overall ESBL-PE prevalence was $47.72 \%$ ( $n=94 / 197)$, with a higher rate among inpatients compared with outpatients (54.13\% vs. 34.37\%). ESBLPE prevalence was highest in older patients ( $\geq 60$ years of age). E. coli was the most common ESBL-producer organism (63.8\%), followed by K. pneumoniae (21.2\%). ESBL-PE were mainly found in urine samples (75\%). The CTXM-1 group was dominant (96.7\% of the 94 ESBL-PE isolates, CTX-M-15 enzyme), followed by the CTX-M-9 group (4. 1\%). $86 \%$ of resistant isolates harbored more than one ESBL-encoding gene. ESBL production was also associated with the highest levels of resistance to non- $\beta$-lactam drugs.

Conclusions: The prevalence of ESBL-PE harboring resistant genes encoding ESBLs of the CTX-M-1 group was high (48\%) among clinical isolates of three main hospitals in Chad, suggesting an alarming spread of ESBL-PE among patients.
\end{abstract}

Keywords: ESBL, Enterobacteriaceae, Clinical samples, Prevalence, Chad

\footnotetext{
* Correspondence: ouchar10@yahoo.fr

${ }^{1}$ Centre Hospitalier Universitaire de Montpellier, Laboratoire de Bactériologie, Université de Montpellier, Montpellier, France

¿UMR MIVEGEC IRD-CNRS-Université de Montpellier, Laboratory of

Bacteriology CHU, Arnaud de Villeneuve 371 avenue du doyen Gaston

Giraud, 34295 Montpellier Cedex 5, France

Full list of author information is available at the end of the article
}

(c) The Author(s). 2019 Open Access This article is distributed under the terms of the Creative Commons Attribution 4.0 International License (http://creativecommons.org/licenses/by/4.0/), which permits unrestricted use, distribution, and reproduction in any medium, provided you give appropriate credit to the original author(s) and the source, provide a link to the Creative Commons license, and indicate if changes were made. The Creative Commons Public Domain Dedication waiver (http://creativecommons.org/publicdomain/zero/1.0/) applies to the data made available in this article, unless otherwise stated. 


\section{Background}

Extended-spectrum ß-lactamase-producing Enterobacteriaceae (ESBL-PE) represent a major problem in the management of nosocomial infections, resulting in prolonged hospital stays, increased hospital charges, and higher mortality and morbidity rates [1]. ESBLs confer resistance to many antibiotics, such as penicillins, cephalosporins and aztreonam, but not to cephamycins, moxalactam and carbapenems. Klebsiella pneumoniae and Escherichia coli are the main ESBL-producing organisms worldwide. Although at a lower frequency, these enzymes have also been detected in several other members of the Enterobacteriaceae family, such as Enterobacter spp., Citrobacter spp., Proteus spp. and Morganella morganii. [2-4]. Therefore, all these species can contribute to ESBL spread in hospital settings. Moreover, due to the coexistence of various modifying enzymes on the same plasmid, ESBL-PE often are resistant also to fluoroquinolones, aminoglycosides, trimethoprim sulfamethoxazole and tetracycline. Thus, ESBL-PE frequently display a multidrug resistance phenotype and are an important cause of treatment failure [5, 6].

ESBLs are encoded by different genes [7] inserted in genetic mobile elements, such as plasmids, that facilitate their spread between bacterial species. The most common ESBLs belong to the CTX-M, SHV and TEM families $[8,9]$. The CTX-M family, particularly CTX-M-15, has emerged worldwide, and is now the most common ESBL type in hospitals and in the community [10]. Although ESBL-mediated bacterial resistance is recognized as an important health problem, limited data are currently available on ESBL-PE prevalence and molecular characterization in Sub-Saharan Africa. Particularly, to our knowledge, there is no study on ESBL-PE prevalence in clinical isolates in Chad.

The purpose of this study was to determine the prevalence and genetic characteristics of ESBL-PE in three main hospitals in Chad.

\section{Methods}

\section{Setting}

This study was conducted in the three main hospitals of Chad from January to March 2017. These three hospitals are located in N'Djamena, the capital city of Chad (1.5 million inhabitants) and are: (i) the National Reference General Hospital (HGRN), a university teaching hospital and one of the first national reference health facility. This hospital has 750 beds, with 8517 admissions and 50,896 outpatients in 2016; (ii) the Mother and Child Hospital (HME), a university teaching hospital and the reference mother-child hospital in Chad. It has a capacity of 261 beds (including an intensive care unit), with about 5000 admissions and 45,000 outpatients in 2016; and (iii) the Renaissance Hospital (HR), a tertiary healthcare facility designed to receive patients with complicated/chronic diseases from other healthcare centers. It has 250 beds and 8 intensive care unit beds. In 2016, 1457 inpatients were admitted among 23,909 consultations.

\section{Sample collection and identification}

We analyzed 1713 consecutive clinical specimens (urine, surgical wound, pus, stool, sperm and blood samples) sent to the microbiology laboratory of each of these three hospitals (HME: $n=623$, HGRN: $n=505$, HR: $n=$ 585). From these specimens, 313 non-duplicated and clinically significant bacterial isolates were obtained. Identification of the bacterial species was performed using biochemical tests and then confirmed by matrix-assisted laser desorption ionization-time of flight (MALDI-TOF) mass spectrometry (Bruker Daltonics, Bremen, Germany).

\section{Antimicrobial susceptibility testing and ESBL-production}

Antimicrobial susceptibility testing was performed with the disk diffusion method on Müller-Hinton agar, as recommended by the European Committee on Antimicrobial Susceptibility Testing (EUCAST) guidelines and using the EUCAST clinical breakpoints (Version 7.1) (http:// www.eucast.org/ clinical_breakpoints/). The following antibiotics were tested: amoxicillin, amoxicillin-clavulanic acid, ticarcillin, ticarcillin-clavulanic acid, piperacillin, piperacillin-tazobactam, temocilin, cephalexin, cefpodoxime, aztreonam, cefotaxime, ceftazidime, cefepime, cefoxitin, ertapenem, imipenem, gentamicin, tobramycin, nethilmycin, amikacin, trimethoprim + sulfamethoxazole, nalidixic acid, ofloxacin, ciprofloxacin, levofloxacin, tetracycline, chloramphenicol and fosfomycin. ESBL production was confirmed with the double-disk synergy method [11]. In the case of high-level production of cephalosporinase, the double-disk synergy test was performed using cloxacillin-supplemented medium $(250 \mathrm{mg} / \mathrm{L})$.

Molecular characterization of ESBL and associated genes DNA was extracted from one single colony of each isolate by incubation in a final volume of $100 \mu \mathrm{L}$ of distilled water at $95^{\circ} \mathrm{C}$ for $10 \mathrm{~min}$ followed by centrifugation. The presence of the $b l a_{\text {СТХ-M }}$ (CTX-M group 1, 2, 8, 9 and 25), bla $a_{\mathrm{TEM}}, b l a_{\mathrm{SHV}}$ and blaOXA-like genes was assessed using a multiplex PCR method following the protocol by Dallenne et al. 2012 [12]. Primers are listed in Table 1 . The cycling conditions were: $95^{\circ} \mathrm{C}$ for 10 min, followed by 30 cycles of denaturation at $95^{\circ} \mathrm{C}$ for $40 \mathrm{~s}$, annealing at $55^{\circ} \mathrm{C}$ for $40 \mathrm{~s}$, elongation at $72^{\circ} \mathrm{C}$ for 1 min, and a final elongation step at $72{ }^{\circ} \mathrm{C}$ for $7 \mathrm{~min}$. DNA samples from reference $b l a_{\mathrm{CTX}-\mathrm{M}}, b l a_{\mathrm{TEM}}, b l a_{\mathrm{SHV}}$ and

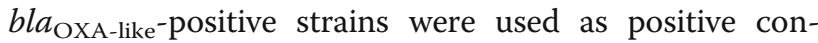
trols. The plasmid-mediated quinolone resistance 
Table 1 Primers used for the detection of $\beta$-lactamase-encoding genes

\begin{tabular}{|c|c|c|c|c|}
\hline PCR & ß-lactamase genes & Primers & Nucleotide sequences & Amplicon size (bp) \\
\hline \multirow[t]{3}{*}{ Multiplex I } & TEM including TEM-1 and TEM-2 & $\begin{array}{l}\text { MultiTSO-T_for } \\
\text { MultiTSO-T_rev }\end{array}$ & $\begin{array}{l}\text { CATTTCCGTGTCGCCCTTATTC } \\
\text { CGTTCATCCATAGTTGCCTGAC }\end{array}$ & 800 \\
\hline & SHV including SHV-1 & $\begin{array}{l}\text { MultiTSO-S_for } \\
\text { MultiTSO-S_rev }\end{array}$ & $\begin{array}{l}\text { AGCCGCTTGAGCAAATTAAAC } \\
\text { ATCCCGCAGATAAATCACCAC }\end{array}$ & 713 \\
\hline & OXA-1, OXA-4 and OXA-30 & $\begin{array}{l}\text { MultiTSO-O_for } \\
\text { MultiTSO-O_re }\end{array}$ & $\begin{array}{l}\text { GGCACCAGATTCAACTTTCAAG } \\
\text { GACCCCAAGTTTCCTGTAAGTG }\end{array}$ & 564 \\
\hline \multirow[t]{3}{*}{ Multiplex II } & CTX-M-1, CTX-M-3 and CTX-M-15 & $\begin{array}{l}\text { MultiCTXMGp1_for } \\
\text { MultiCTXMGp1-2_rev }\end{array}$ & $\begin{array}{l}\text { TTAGGAARTGTGCCGCTGYA } \\
\text { CGATATCGTTGGTGGTRCCAT }\end{array}$ & 688 \\
\hline & CTX-M-2 & $\begin{array}{l}\text { MultiCTXMGp2_for } \\
\text { MultiCTXMGp1-2_re }\end{array}$ & $\begin{array}{l}\text { CGTTAACGGCACGATGAC } \\
\text { CGATATCGTTGGTGGTRCCAT }\end{array}$ & 404 \\
\hline & CTX-M-9 and CTX-M14 & $\begin{array}{l}\text { MultiCTXMGp9_for } \\
\text { MultiCTXMGp9_rev }\end{array}$ & $\begin{array}{l}\text { TCAAGCCTGCCGATCTGGT } \\
\text { TGATTCTCGCCGCTGAAG }\end{array}$ & 561 \\
\hline CTX-M-8/25 & CTX-M-8/25 & $\begin{array}{l}\text { CTX-Mg8/25_for } \\
\text { CTX-Mg8/25_re }\end{array}$ & $\begin{array}{l}\text { AACRCRCAGACGCTCTAC } \\
\text { TCGAGCCGGAASGTGTYAT }\end{array}$ & 326 \\
\hline
\end{tabular}

(PMQR) gene (qnr $(A, B, C, D, S)$, aac (6')-Ib-cr, $q e p A$ and $o q x A B)$ and the aminoglycoside resistance-conferring $16 \mathrm{~S}$ rRNA methylase genes ( $\operatorname{arm} A$, $r m t B$ and $r m t C$ ) were assessed using PCRs as previously described [13, 14]. PCR products were visualized after electrophoresis (100 V for $90 \mathrm{~min}$ ) on $2 \%$ agarose gels containing ethidium bromide. A $100 \mathrm{bp}$ DNA ladder (Promega, USA) was used as marker size. PCR products were sequenced bidirectionally on a 3100 ABI Prism Genetic Analyzer (Applied Biosystems). The sequencing data were analyzed online using the BLAST tool available at the National Center for Biotechnology Information web page (https://blast.ncbi.nlm.nih.gov/Blast.cgi).

\section{Statistics}

Statistical analyses were performed using the Epi Info software, version 3.5.3 (Centers for Disease Control and Prevention, Atlanta, GA, USA). Differences in the proportion of ESBL-producers between patient groups were assessed using the Chi-square test, while associations between the presence of ESBL-encoding genes and categorical variables (sex, age and source of infection) were tested using multinomial logistic regressions. A $p$ value $<0.05$ was considered as statistically significant.

\section{Results}

\section{Bacterial isolates}

MALDI-TOF mass spectrometry analysis of the 313 clinically significant isolates showed that 197 were Enterobacteriaceae, whereas the other 116 isolates included Gram-positive cocci (Enterococcus spp., Staphylococcus spp. and Streptococcus spp) and Gram-negative bacilli (Pseudomonas aeruginosa and Acinetobacter baumanii). Among the 197 Enterobacteriaceae isolates, 134 were from inpatients' and 63 from outpatients' samples. Enterobacteriaceae isolates were recovered from urine $(n=143)$, pus $(n=44)$, blood $(n=7)$, stool $(n=1)$, wound $(n=1)$ and sperm $(n=1)$ samples. The age of these 197 patients ranged from 1 to 83 years, and $52.79 \%$ were men (Table 2). Raw data in Additional file 1.

\section{ESBL-PE prevalence}

Among the 197 Enterobacteriaceae isolates, 94 (47.7\%) were defined as presumable ESBL-PE on the basis of the antimicrobial susceptibility testing results. Molecular analysis confirmed that these 94 isolates carried ESBL-encoding genes. ESBL-PE prevalence was not significantly different in the three hospitals: 55\% (38/69) at HGRN, 48\% (22/46) at HR, and 41\% (34/82) at HME (Table 2). The proportion of ESBL-PE isolates was higher in inpatients than outpatients $(54.13 \%$ vs. $34.37 \%$,

Table 2 Characteristics of the patients infected by ESBL-PE and non-ESBL-PE

\begin{tabular}{|c|c|c|c|c|}
\hline Variables & $\begin{array}{l}\text { ESBL-PE } \\
(n=94)\end{array}$ & $\begin{array}{l}\text { Non- ESBL-PE } \\
(n=103)\end{array}$ & $\begin{array}{l}\text { Odds Ratio } \\
(95 \% \mathrm{Cl})\end{array}$ & $P$-value \\
\hline Sex & & & & 0.071 \\
\hline Women $(n=93)$ & 38 & 55 & 1 & \\
\hline Men $(n=104)$ & 56 & 48 & $1.68(0.95-2.95)$ & \\
\hline \multicolumn{5}{|l|}{ Age group (years) } \\
\hline$<15(n=39)$ & 12 & 27 & 1 & \\
\hline $15-<60(n=131)$ & 63 & 68 & $1.97(0.92-4.24)$ & 0.08 \\
\hline$\geq 60(n=27)$ & 19 & 8 & $5.14(1.76-15.03)$ & 0.002 \\
\hline \multicolumn{5}{|l|}{ Hospital } \\
\hline $\operatorname{HME}(n=82)$ & 34 & 48 & 1 & \\
\hline $\mathrm{HR}(n=46)$ & 22 & 24 & $1.29(0.62-2.67)$ & 0.48 \\
\hline HGRN $(n=69)$ & 38 & 31 & $1.73(0.90-3.30)$ & 0.09 \\
\hline \multicolumn{5}{|l|}{ Patient type } \\
\hline $\begin{array}{l}\text { Outpatients } \\
(n=64)\end{array}$ & 22 & 42 & 1 & \\
\hline $\begin{array}{l}\text { Inpatients } \\
(n=133)\end{array}$ & 72 & 61 & $2.25(1.21-4.18)$ & 0.01 \\
\hline
\end{tabular}


$p<0.001)$, and in older patients ( $\geq 60$ years of age) than in the other two age groups $(\mathrm{OR}=5.14,95 \% \mathrm{CI}=1.76-$ 15.03, $p=0.002)$. Sex was not significantly associated with ESBL-PE presence $(p=0.071)$ (Table 2).

Among the 94 ESBL-PE, E. coli was the predominant species $(n=60,63.83 \%)$, followed by $K$. pneumoniae ( $n$ $=20,21.28 \%), M$. morganii $(n=5,5.32 \%)$, Enterobacter cloacae $(n=4,4.26 \%)$, Providencia rettgeri $(\mathrm{n}=2,2.13 \%)$, Proteus mirabilis $(n=1,1.06 \%)$, Enterobacter aerogenes $(\mathrm{n}=1,1.06 \%)$ and Citrobacter koseri $(\mathrm{n}=1,1.06 \%)$. Moreover, 70 of the 94 ESBL-PE isolates (74.47\%) were from urine and 21 (22.34\%) from pus samples (Table 3).

\section{Resistance patterns in ESBL-producing and non-ESBL- producing Enterobacteriaceae}

Resistance to antibiotics that are not hydrolyzed by ESBLs was more frequent in ESBL-PE than in non-ESBL-PE isolates, except for fosfomycin (Fig. 1). The rates of resistance to $\beta$-lactam antibiotics in ESBL-PE and non-ESBL-PE isolates were 93.62 and $27.18 \%$ for nalidixic acid, 89.36 and $19.42 \%$ for ofloxacin, 88.3 and $18.45 \%$ for ciprofloxacin, 80.85 and $18.45 \%$ for levofloxacin, 91.49 and $55.34 \%$ for sulfonamides, 74.47 and $12.62 \%$ for tobramycin, 70.21 and $13.59 \%$ for gentamicin, 67.02 and $6.8 \%$ for nethilmycin, and 18.09 and $0.97 \%$ for amikacin, respectively. Furthermore, the resistance rates of ESBL-PE isolates from inpatients and outpatients were 91.67 and $100.00 \%$ for nalidixic acid, 90.28 and $81.82 \%$ for ciprofloxacin, 73.61 and $59.09 \%$ for gentamicin, 15.28 and $27.27 \%$ for amikacin, and 80.56 and $95.46 \%$ for tetracycline. Therefore, the resistance rates in ESBL-PE and non-ESBL for cefoxitin, ertapenem and temocillin were $23,4 \%$ and $23,3 \%, 6,38 \%$ and $0,00 \%, 8,51$ and $0,00 \%$, respectively.

\section{Characterization of ESBL-encoding genes}

The results of the PCR and sequencing analyses showed that the CTX-M group 1 was the most common (96.4\% of isolates) ESBL type, and all the CTX-M-positive isolates carried the $b l a_{\text {CTX-M-15 }}$ gene (Table 4). CTX-M group 9 was present in $4.1 \%$ of all ESBL-PEs (bla $a_{\mathrm{CTX}-\mathrm{M}-27}$ and $\left.b l a_{\mathrm{CTX}-\mathrm{M}-14}\right)$. The $b l a_{\mathrm{CTX}-\mathrm{M}-27}$ gene was detected only in $E$. coli isolates, and the $b l a_{\mathrm{CTX}-\mathrm{M}-14}$ gene only in $K$. pneumoniae isolates. The $b l a_{\mathrm{SHV}}, b l a_{\mathrm{CTX}-\mathrm{M}}$ group 2, 8 and 25 genes were not detected in any of the ESBL-PE isolates. $86 \%$ of isolates carried more than one were associated with one to two other $ß$-lactamase genes $\left(b l a_{\text {TEM-1 }}\right.$ and $\left.b l a_{\mathrm{OXA}-1}\right), 62 \%$ were associated with one to three PMQR ( $q n r B, q n r D, q n r S$, aac(6')-ib-cr, oqxAB and qepA) and 9\% carried one to two $16 \mathrm{~S}$ rRNA methylase genes (armA, rmtB and $r m t C)$ Table 4. Two E. coli isolates harbored the $b l a_{\mathrm{CTX}-\mathrm{M}-15}$ gene in association with bla $_{\mathrm{CTX}-\mathrm{M}-27}$, while one $K$. pneumoniae isolate carried the $b l a_{\mathrm{CTX}-\mathrm{M}-14}$ gene alone.

\section{Discussion}

The study reveals an ESBL-PE prevalence of $48 \%$ among clinical isolates in three major Chadian hospitals. Our results also confirm the spread of CTX-M-15 genes in isolates from African patients, and the finding that ESBL-PE display co-resistance to other antibiotic classes.

ESBL-PE prevalence varies widely between geographic areas. Low prevalence rates have been reported in Europe, USA and North America [15, 16], while high rates are usually observed in South America, Asia [17] and some African countries [18]. In Sub-Saharan Africa, and particularly in Central Africa, limited data are available on ESBL-PE. The prevalence found in our study (48\%) is similar to the one reported for other African countries, such as Ghana (49.4\%) [19], Gabon (50\%) [20], Burkina Faso (58\%) [21] and Cameroon 55.3\% [22], and higher than in Nigeria (20.9\%) [23] and Central African Republic (19.3\%) [24]. Therefore, it confirms the spread of these bacteria in the African continent. A possible explanation for such high ESBL-PE prevalence is the high selective pressure generated by an important use of

Table 3 Distribution of ESBL-PE isolates according to the Enterobacteriaceae species and sample type

\begin{tabular}{|c|c|c|c|c|c|c|}
\hline \multirow[t]{3}{*}{ Species } & \multicolumn{6}{|l|}{ Sample } \\
\hline & Urine & Pus & Blood & Wound & Sperm & Total (n\%) \\
\hline & n (\%) & n (\%) & n (\%) & n (\%) & n (\%) & \\
\hline Escherichia coli & $45(64.2)$ & $12(60.0)$ & $1(50.0)$ & $1(100.0)$ & $1(100.0)$ & $60(63.8)$ \\
\hline Klebsiella pneumonia & $15(21.4)$ & $5(25.0)$ & $0(0)$ & $0(0)$ & $0(0)$ & $20(21.2)$ \\
\hline Morganella morganii & $4(5.7)$ & $1(5.0)$ & $0(0)$ & $0(0)$ & $0(0)$ & $5(5.3)$ \\
\hline Enterobacter cloacae & $2(2.8)$ & $1(5.0)$ & $1(50.0)$ & $0(0)$ & $0(0)$ & $4(4.2)$ \\
\hline Providencia rettgeri & $2(2.8)$ & $0(0)$ & $0(0)$ & $0(0)$ & $0(0)$ & $2(2.1)$ \\
\hline Proteus mirabilis & $1(1.4)$ & $0(0)$ & $0(0)$ & $0(0)$ & $0(0)$ & $1(1.0)$ \\
\hline Enterobacter aerogenes & $1(1.4)$ & $0(0)$ & $0(0)$ & $0(0)$ & $0(0)$ & $1(1.0)$ \\
\hline Citrobacter koseri & $0(0)$ & $1(5.0)$ & $0(0)$ & $0(0)$ & $0(0)$ & $1(1.0)$ \\
\hline Total & $70(100.0)$ & $20(100.0)$ & $2(100.0)$ & $1(100.0)$ & $1(100.0)$ & $94(100.0)$ \\
\hline
\end{tabular}




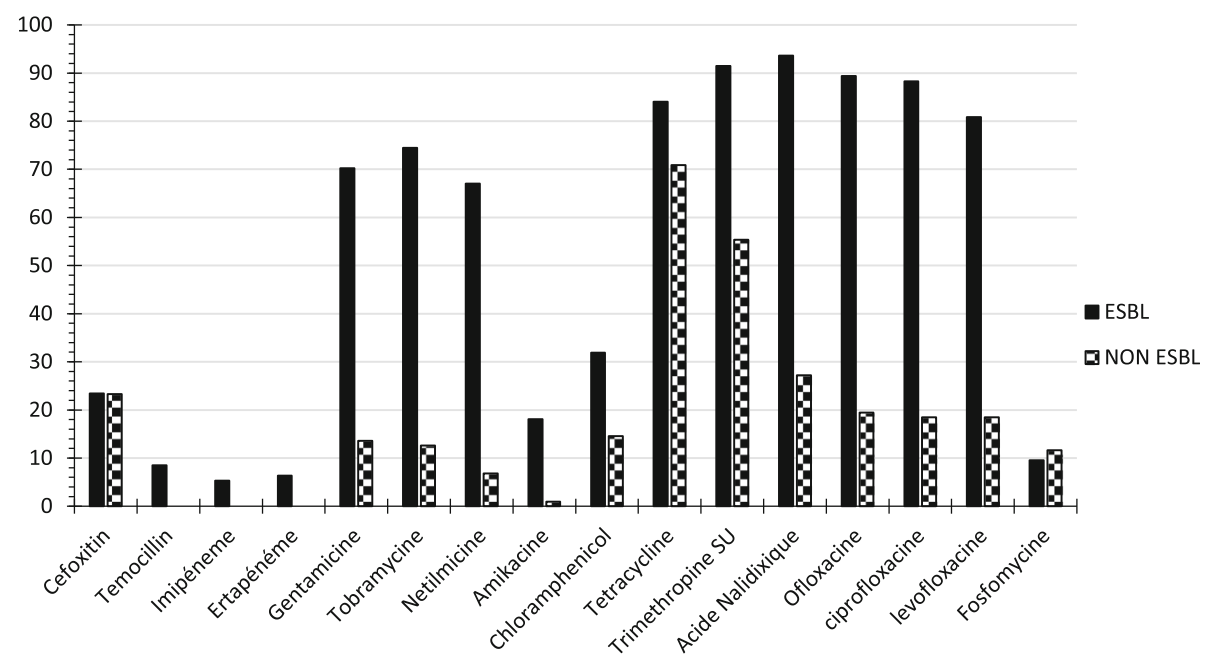

Fig. 1 Antimicrobial resistance rates of ESBL-producing and non-ESBL-producing Enterobacteriaceae to other molecules

Table 4 Distribution of resistance genes in the 94 ESBL-producer isolates

\begin{tabular}{|c|c|c|c|}
\hline \multirow[t]{2}{*}{ Isolates (n) } & \multicolumn{3}{|l|}{ Genes involved } \\
\hline & $\beta$-lactamase genes & PMQR & 16S rRNA methylase \\
\hline \multirow[t]{11}{*}{ E. coli $(60)$} & CTX-M-15 (1) & gnrs (2) & $\operatorname{armA}(2)$ \\
\hline & CTX-M-27 (3) & $\operatorname{oqx} A B(1)$ & $r m t C(2)$ \\
\hline & CTX-M-15/TEM-1 (14) & qepA (1) & $\operatorname{armA} / \mathrm{rmtC}(1)$ \\
\hline & CTX-M-9/TEM-1 (2) & $a a c\left(6^{\prime}\right)-1 b-c r(24)$ & \\
\hline & CTX-M-15/OXA-1 (17) & anrS/aac (6')-Ib-cr (4) & \\
\hline & CTX-M-15/CTX-M-27/TEM-1 (2) & qnrS/oqxAB (1) & \\
\hline & CTX-M-15/TEM-1/OXA-1 (19) & qnrB/oqxAB (1) & \\
\hline & TEM-1 (1) & qnrB/oqxAB/aac $\left(6^{\prime}\right)-\operatorname{lb}-\operatorname{cr}(2)$ & \\
\hline & OXA-1 (1) & oqxAB/aac $\left(6^{\prime}\right)-1 b-c r(1)$ & \\
\hline & & oqxAB/gnrs (1) & \\
\hline & & qepAaac $\left(6^{\prime}\right)-1 b-c r(1)$ & \\
\hline \multirow[t]{7}{*}{ K. pneumonia (20) } & CTX-M-15 (4) & oqxAB (1) & $r m t B(1)$ \\
\hline & CTX-M-14 (1) & gnrs/ogxAB/ (3) & $r m t C(1)$ \\
\hline & CTX-M-15/TEM-1 (5) & qnrS/oqXAB/aac $\left(6^{\prime}\right)-1 b-c r(1)$ & \\
\hline & CTX-M-15/OXA-1 (2) & anrB/aac $\left(6^{\prime}\right)-\operatorname{lb}-\mathrm{cr}(1)$ & \\
\hline & CTX-M-15/TEM-1/OXA-1 (8) & $9 n r B / o q \times A B(1)$ & \\
\hline & & qnrB/oqxAB/aac $\left(6^{\prime}\right)-\operatorname{lb}-\mathrm{cr}(5)$ & \\
\hline & & oqxAB/aac $\left(6^{\prime}\right)-\operatorname{lb}-\operatorname{cr}\left({ }^{\prime \prime}\right)$ & \\
\hline \multirow[t]{4}{*}{ Other species (14) } & CTX-M-15/TEM-1 (6) & $a a c\left(6^{\prime}\right)-1 b-c r(2)$ & $r m t B(1)$ \\
\hline & CTX-M-15/OXA-1 (3) & anrB/aac $\left(6^{\prime}\right)-1 b-c r(1)$ & $\operatorname{armA} / \mathrm{rmtC}(1)$ \\
\hline & CTX-M-15/TEM-1/OXA-1 (3) & anrD/aac $\left(6^{\prime}\right)-1 b-c r(2)$ & \\
\hline & OXA-1 (2) & & \\
\hline
\end{tabular}


beta-lactam antibiotics in African countries, where they are frequently proposed as first-line treatment for bacterial infections caused by Enterobacteriaceae [25]. Other factors that contribute to their spread include non-prescription antimicrobial use, self-medication, poor hygiene, high burden of infectious diseases, consumption of counterfeit drugs, lack of antimicrobial resistance detection systems, and absence of diagnostic tools [26-28].

E. coli and $K$. pneumoniae were the most common ESBL-PE isolates and most of these isolates were from urine samples, in agreement with previous findings in India [29]. Urinary Tract Infection (UTI) is the most frequent bacterial infection worldwide in patients with nosocomial and community-acquired infections, and $E n$ terobacteriaceae (mainly E. coli and K. pneumoniae) are generally the causal agent [30,31].

ESBL-PE prevalence was significantly higher in isolates from inpatient than outpatient, as previously reported in Ghana and Rwanda [19, 31]. This pattern could be explained by the extensive use of ceftriaxone and cefotaxime as empirical antibiotic treatment in Chadian hospitals. Moreover, hospitalization has been identified as a high-risk factor for ESBL-PE infection, because ESBL-encoding genes are carried via plasmids that can be easily disseminated among the different bacteria that contaminate hospitalized patients [26, 32]. Both factors could be operating at the same time, and further research is needed to determine their contribution to the observed pattern. Like in previous studies, ESBL-PE were more frequent $(p=0.002)$ in isolates from older patients ( $\geq 60$ years of age) [33]. This could be explained by the frequent administration of antibiotic therapy to older patient.

Regarding the association of resistance to different antibiotic classes, this study shows a positive association between ESBL-PE and resistance to quinolones, aminoglycosides (except amikacin), tetracycline, chloramphenicol and co-trimoxazole (trimethoprim/sulfamethoxazole), as previously reported in Burkina Faso and Gabon [21, 34]. The resistance to other antibiotic classes in ESBL-PE isolates is alarming, because it could further restrict the choice of adequate empirical therapy for the treatment of infections caused by these bacteria. In our study, isolates were susceptible to imipenem, ertapenem and amikacin. However, these drugs should be used with caution for empirical treatments in order to avoid emergence of carbapenem-resistant Enterobacteriaceae.

In our study, the most common resistance gene (bla $a_{\mathrm{CTX}-\mathrm{M}-15}$ in $96.7 \%$ of isolates) belonged to the CTX-M family. CTX-M-15 is now considered endemic in many countries and is rapidly disseminating among different Enterobacteriaceae species [14]. Similar to our study, high proportions of $b l a_{\mathrm{CTX}-\mathrm{M}-15}$-positive clinical isolates were reported in other Sub-Saharan African countries: Cameroon (96\%) [22], Gabon (84.1\%) [33],
Burkina Faso (94\%) [21], Ghana (98\%) [32], and Nigeria (79\%) [35].

The interpretation of the findings of this study is limited by the fact that there was no knowledge of the patients' previous antibiotic treatments. Indeed, antibiotic treatments prior to sample collection could have favored the transient selection of resistant bacteria, and thus increased ESBL-PE prevalence compared with patients who were not previously treated with antibiotics.

\section{Conclusions}

This report reveals a high ESBL-PE prevalence (48\%) and the predominance of the CTX-M-15 enzyme among clinical isolates in three major Chadian hospitals. This emphasizes the urgent need to rationalize the use of antibiotics in hospital settings and to implement a national surveillance system for antibiotic-resistant bacteria to develop empirical treatment guidelines.

We also recommend further investigations to monitor carbapenem resistance and to determine whether healthy individuals act as ESBL-PE reservoirs in the community. These studies will contribute to better understand the mechanisms responsible for the spread of ESBL-PE in hospitals and communities.

\section{Additional file}

Additional file 1: Raw data generated and analyzed during the current study. (XLSX $35 \mathrm{~kb}$ )

\section{Abbreviations}

ESBL-PE: extended-spectrum ß-lactamase-producing Enterobacteriaceae; HGRN: National Reference General Hospital; HME: Mother and Child Hospital; HR: Renaissance Hospital; MALDI-TOF: matrix-assisted laser desorption ionization-time of flight; OR: Odd ratio

\section{Acknowledgments}

We would like to thank IRD and CHU. We thank Elisabetta Andermarcher for assistance in preparing and editing the manuscript.

\section{Funding}

This study was supported by a grant from Islamic Development Bank (IDB). The IDB were not involved in the study design, collection, analysis, interpretation of data and in writing the manuscript.

\section{Availability of data and materials}

All data generated or analysed during this study are included in this published article and its Additional file 1.

\section{Authors' contributions}

OOM, CC, MH, JPH and GS Conceived and designed the experiments. OOM, $M L, K K$ and MA Performed the experiments. OOM, ML, YD, AT, JB, JS, ALB, CC and GS Contributed to the writing of the manuscript. All authors read and approved the final manuscript.

\section{Ethics approval and consent to participate}

This study was approved by the ethics board of each hospital and by the Chadian Ministry of Public Health (N 676/PR/PM/MSP/SE/SG/DRGP/DRH/ SGF/16). Informed written consent was obtained from all subjects and from at least one parent for each child before enrolment in the study. 


\section{Consent for publication}

Not applicable.

\section{Competing interests}

The authors declare that they have no competing interests.

\section{Publisher's Note}

Springer Nature remains neutral with regard to jurisdictional claims in published maps and institutional affiliations.

\section{Author details}

${ }^{1}$ Centre Hospitalier Universitaire de Montpellier, Laboratoire de Bactériologie, Université de Montpellier, Montpellier, France. ${ }^{2}$ UMR MIVEGEC IRD-CNRS-Université de Montpellier, Laboratory of Bacteriology CHU, Arnaud de Villeneuve 371 avenue du doyen Gaston Giraud, 34295 Montpellier Cedex 5, France. ${ }^{3}$ Service de laboratoire, Hôpital de la Mère et de l'Enfant, N'Djaména, Chad. ${ }^{4}$ Faculté de Médecine, Université de N'Djaména, N'Djaména, Chad. ${ }^{5}$ Service de laboratoire, Hôpital Général des Références Nationale, N'Djaména, Chad. '5ervice de laboratoire, Hôpital de la Renaissance, N'Djaména, Chad. Departamento de Ecología y Biodiversidad, Facultad de Ciencias de la Vida, Universidad Andrés Bello, Santiago, Chile. ${ }^{8}$ Centre Hospitalier Universitaire de Montpellier, Département Bio-pathologie cellulaire et tissulaire des tumeurs, Université de Montpellier, Montpellier, France. ${ }^{9}$ Laboraoire Mixte International DRISA, IRD, Montpellier, France.

\section{Received: 15 July 2018 Accepted: 20 February 2019}

\section{Published online: 28 February 2019}

\section{References}

1. Ramphal R, Ambrose PG. Extended-spectrum $\beta$-lactamases and clinical outcomes: current data. Clin Infect Dis. 2006;42(Suppl 4):64-72.

2. Phillipon A, Labia R, Jacoby G. Extended-spectrum -lactamases. Antimicrob Agents Chemother. 1989;33:1131-6.

3. Bush K, Jacoby GA. Updated functional classification of beta-lactamases. Antimicrob Agents Chemother. 2010;54:969-76.

4. Pitout JD, Laupland KB. Extended-spectrum-lactamase-producing Enterobacteriaceae: an emerging public-health concern. Lancet Infect Dis. 2008;8:159-66

5. Bush K, Fisher JF. Epidemiological expansion, structural studies, and clinical challenges of new -lactamases from gram-negative bacteria. AnnuRev Microbiol. 2011;65:455-78.

6. Paterson DL, Bonomo RA. Extended-spectrum beta-lactamases: a clinical update. Clin Microbiol Rev. 2005;18:657-86.

7. Colodner R, Rock W, Chazan B, Keller N, Guy N, Sakran W, et al. Risk factors for the development of extended-spectrum beta-lactamase-producing bacteria in nonhospitalized patients. Eur J Clin Microbiol Infect Dis. 2004 23(3):163-7.

8. Zhao W-H, Hu Z-Q. Epidemiology and genetics of CTX-M extendedspectrum $\beta$-lactamases in gram-negative bacteria. Crit Rev Microbiol. 2013; 39(1):79-101.

9. Bonnet R. Growing group of extended-spectrum beta-lactamases: the CTXM enzymes. Antimicrob Agents Chemother. 2004:48:1-14.

10. Canton R, Coque TM. The CTX-M Beta-lactamase pandemic. Curr Opin Microbiol. 2006;9:466-75

11. Jarlier V, Nicola MH, Fournier G, Philippon A. Extended broad-spectrum b-lactamases conferring transferable resistance to newer b-lactam agents in Enterobacteriaceae: hospital prevalence and susceptibility patterns. Rev Infect Dis. 1988;10:867-78.

12. Dallenne C, Da Costa A, Decre D, Favier C, Arlet G. Development of a set of multiplex PCR assays for the detection of genes encoding important betalactamases in Enterobacteriaceae. J Antimicrob Chemother. 2010;65: 490-5.

13. Ciesielczuk H, Hornsey M, Choi V, Woodford N, Wareham DW. Development and evaluation of a multiplex PCR for eight plasmid-mediated quinolonesresistance determinants. J Med Microbiol. 2013;62:1823-7.

14. Doi Y, Arakawa Y. 165 ribosomal RNA methylation: emerging resistance mechanism against aminoglycosides. Clin Infect Dis. 2007;45:88-94.

15. European Centre for Disease Prevention and Control. Antimicrobial resistance surveillance in Europe. Annual report of the European antimicrobial resistance surveillance network (EARS-net). Stockholm: ECDC. 2010. p. 2011
16. Coque T, Baquero F, Canton R. Increasing prevalence of ESBL-producing Enterobacteriaceae in Europe. Euro Surveill 2008;13(47):pii=19044. https://doi. org/10.2807/ese.13.47.19044-en

17. Jean SS, Hsueh PR. High burden of antimicrobial resistance in Asia. Int JAntimicrob Agents. 2011;37(4):291-5.

18. Leopold $\mathrm{SJ}$, van Leth $\mathrm{F}$, Tarekegn $\mathrm{H}$, et al. Antimicrobial drug resistance among clinically relevant bacterial isolates in sub-Saharan Africa: a systematic review. J Antimicrob Chemother. 2014;69:2337-53.

19. Obeng-Nkrumah N, Twum-Danso K, Krogfelt KA, Newman MJ. High levels of extended-spectrum beta-lactamases in a major teaching hospital in Ghana: the need for regular monitoring and evaluation of antibiotic resistance. AmJTrop Med Hyg. 2013;89:960-4.

20. Alabi AS, Frielinghaus L, Kaba H, Kösters K, Huson MAM, Kahl BC, Peters G, Grobusch MP, Issifou S, Kremsner PG, Schaumburg F. Retrospective analysis of antimicrobial resistance and bacterial spectrum of infection in Gabon Central Africa. BMC Infect Dis. 2013;13:455.

21. Ouedraogo AS, Sanou M, Kissou A, Sanou S, Solare H, Kabore F, et al. High prevalence of extendedspectrum $\beta$-lactamase producing Enterobacteriaceae among clinical isolates in Burkina Faso. BMC Infect Dis. 2016;16:326.

22. Lonchel CM, Melin P, Gangoué-Piéboji J, Assoumou MCO, Boreux R, De Mol $P$. Extended-spectrum $\beta$-lactamase-producing Enterobacteriaceae in Cameroonian hospitals. Eur J Clin Microbiol Infect Dis. 2013;32:79-87.

23. Ogbolu DO, Daini OA, Ogunledun A, et al. High levels of multidrug resistance in clinical isolates of gram-negative pathogens from Nigeria. Int J Antimicrob Agents. 2011;37:62-6.

24. Raymond B, Dahlia M, Alexandre M, et al. Increasing prevalence of antimicrobial resistance among Enterobacteriaceae uropathogens in Bangui. Central African Republic J Infect Dev Ctries. 2009;3(3):187-90. https://doi. org/10.3855/jidc.34.

25. Benavides JA, Godreuil S, Bodenham R, Ratiarison S, Devos C, Petretto MO Raymond R, Escobar-Páramo P. No evidence for transmission of antibioticresistant Escherichia Coli strains from humans to wild Western lowland gorillas in Lopé National Park, Gabon. Appl Environ Microbiol. 2012;78(12):4281-7.

26. Tolbert S, Happiness K, Marco VZ, Michael A, Ole L, Gibson K, Frank MA. Meta-analysis of proportion estimates of extended-Spectrum-Beta-lactamase producing Enterobacteriaceae in East Africa hospitals. Antimicrob Resist Infect Control. 2016:5:18.

27. Ouedraogo AS, Jean Pierre H, Banuls AL, Ouedraogo R, Godreuil S. Emergence and spread of antibiotic resistance in West Africa: contributing factors and threat assessment. Medecine et SanteTropicales. 2017;27(2): 147-54. https://doi.org/10.1684/mst.2017.0678.

28. Ndir A, Diop A, Ka R, Faye PM, Dia-Badiane NM, Ndoye B, et al. Infections caused by extended-spectrum beta-lactamases producing Enterobacteriaceae: clinical and economic impact in patients hospitalized in 2 teaching hospitals in Dakar, Senegal. Antimicrob Resist Infect Control. 2016;5:13

29. Shobha KL, Ramachandra L, Rao G, Majumder S, Rao SP. Extended Spectrum Beta-lactamases (ESBL) in gram negative bacilli at a tertiary care hospital. Journal of Diagnostic and Clinical Research. 2009;3:1307-12.

30. Khurana S, Taneja N, Sharma M. Extended Spectrum $\beta$-lactamase mediated resistance in urinary tract isolates of family Enterobacteriaceae. Indian J Med Res. 2002:116:145-9.

31. Muvunyi CM, Masaisa F, Bayingana C, Mutesa L, Musemakweri A, Muhirwa G, Claeys GW. Decreased susceptibility to commonly used antimicrobial agents in bacterial pathogens isolated from urinary tract infections in Rwanda: need for new antimicrobial guidelines. AmJTrop Med Hyg. 2011;84:923-8.

32. Agyekum A, Fajardo-Lubián A, Ansong D, Partridge SR, Agbenyega T, Iredell JR. blaCTX-M-15 carried by IncF-type plasmids is the dominant ESBLgene in Escherichia coli and Klebsiella pneumoniae at a hospital in Ghana. DiagnMicrobiol Infect Dis. 2016;84:328.

33. Kaye KS, Schmader KE, Sawyer R. Surgical site infection in the elderly population. Clin Infect Dis. 2004;39(12):1835-41.

34. Schaumburg F, Alabi A, Kokou C, Grobusch MP, Köck R, Kaba H, Becker K, Adegnika AA, Kremsner PG, Peters G, Mellmann A. High burden of extendedspectrum $\beta$-lactamase-producing Enterobacteriaceae in Gabon. J Antimicrob Chemother. 2013:68:2140-3.

35. Raji MA, Jamal W, Ojemeh $O$, Rotimi VO. Sequence analysis of genes mediating extended-spectrum beta-lactamase (ESBL) production in isolates of Enterobacteriaceae in a Lagos teaching hospital, Nigeria. BMC Infect Di. 2015;15:259 